\title{
Intermediate osteopetrosis
}

INSERM

\section{Source}

INSERM. (1999). Orphanet: an online rare disease and orphan drug data base.

Intermediate osteopetrosis. ORPHA:210110

Intermediate osteopetrosis is a rare, genetic primary bone dysplasia with increased bone density characterized by susceptibility to fractures after minor trauma, anemia, and characteristic skeletal radiographic changes, such as sandwich vertebra, bone-withinbone appearance, Erlenmeyer-shaped femoral metaphysis, and mild osteosclerosis of the skull base. Dental anomalies and visual impairment secondary to optic nerve compression have been rarely described. 